\title{
EXPERIMENTAL RESEARCH ON INSUFFICIENT WATER LUBRICATION OF MARINE STERN TUBE JOURNAL BEARING WITH ELASTIC POLYMER BUSH
}

Agnieszka Barszczewska

Gdańsk University of Technology, Poland

\begin{abstract}
Water-lubricated bearings with polymer bushes are steadily gaining popularity due to their advantages, including environmental friendliness, relatively simple construction and long-term operation. Nevertheless, in practice instances of damage to such bearings occur due to insufficient or absent flow of the lubricating agent. In this study, experimental tests established that elastic polymer bush bearing is capable of operating without excessive wear for a period of at least 60 minutes under conditions of marginal water flow and typical loads for stern tube journal bearings of small ships.
\end{abstract}

Keywords: lubrication failure,bearing seizure,water-lubricated bearing,non-metallic bearing,sliding bearing

\section{INTRODUCTION}

Water-lubricated polymer bush bearings are increasingly popular and widely employed in shipbuilding (as bearings of propeller shafts), hydro-power plants (guide bearings of turbine shafts) [1-3], as well as in water pump shafts. Because they use water as the lubricating agent, they provide the undoubted advantage of being environmentally friendly. In most cases, lubrication takes place in an open system, making use of the surrounding water (vessels) or working fluid (turbines and pumps). As a result, there is no danger of contaminating the natural environment with petroleum compounds, as may be the case with oil-lubricated white metal bearings. Polymer bushes are relatively easy to install and, as pointed out by Ogle et al. [1], the operating costs of such bearings may be lower, taking into account their lack of costs connected with oil use (purchase, service, potential costs of repairing seal breakdowns). In addition, as Roldo et al. [4] observed, the use of polymer bushes in stern tube propeller shaft bearings may result in reducing friction loss by a factor of 6 or even 9 , in comparison to white metal bush bearings. In connection with increasingly stringent regulations on protecting the marine environment, bearings manufacturers have for a number of years proposed the comprehensive replacement of oil-lubricated bearings with water-lubricated ones, declaring their comparable hydrodynamic load capacity [5-7].

The wear process of a propeller shaft bearing bush is a natural phenomenon due to the propeller shaft's variable speeds and loads, as well as its frequent start-up periods. Upon reaching the limit of a certain wear depth, the old bushes are replaced with new ones. In this way, a properly designed and installed polymer bush bearing may function for periods exceeding twenty years.

However, polymer bushes can undergo unexpected, rapid wear, which in extreme cases may lead to overheating and melting of the bush material. Root causes of such breakdowns can include design stage construction faults, improper bush processing and installation [8], adverse operating conditions, etc.

Adverse operating conditions include i.a., deformation of the ship hull, a contaminated lubricating agent or insufficient lubricant flow through the bearing. 
Deformations of elastic ship hulls result in misalignment of the rigid propeller shaft in relation to the bush [9]. Such situation of the shaft not being positioned axially in relation to the bush may lead to a decrease in the minimum lubricating film thickness, pressure distribution deformation, and in certain cases to a significant decrease in the bearing's hydrodynamic load-carrying capacity [10-12]. In extreme cases, local contact between the shaft and the bush at its edge - often called shaft edging, might occur, along with rapidly progressing bush wear, due to locally exceeding maximum allowed pressure values [13].Contamination of the lubricating agent with solid particles, such as sand $[14,15]$ can accelerate wear of the polymer bush as well. The research findings of Dong et al. [14] demonstrate that rapidly progressing wear occurs in cases of higher sliding speeds or greater applied loads. A fast rate of wear progression may also be induced by the presence of a small amount of wear particles in the lubricating film [16]. The progress of the bush wearing process depends on the size, shape and number of these particles.

Additionally, limited water flow through the bearing may lead to rapid wear of the bush. When a water pump breakdowns or some water contaminations enter the shaft stern tube, the water flow through the bearing is limited or even stopped. Moreover, the water flow might be accidentally limited by a member of the ship's crew.

An example of propeller shaft bearing damage resulting from limited water flow was presented by Młynarczak [17]. Three closed-circuit water-lubricated composite bearings installed in the propeller shaft of a bulk carrier experienced sudden failure despite the presence of numerous protection mechanisms against lubrication system breakdowns. The bearing lubrication system was equipped with two circulation pumps in case of the failure of one of them, as well as with seawater inflow to provide a lubricating agent in the event of breakdown of the shaft stern tube seal and leakage of fresh water from the lubrication system. Due to the fact that seawater contains various contaminations which may settle in the stern tube and limit the water flow, the lubrication system was additionally equipped with two lines bypassing the stern tube, allowing the contaminations from the stern tube to be washed out in the opposite direction. After analysing the post-failure incident documentation, Młynarczak pointed out that the designed system allowed for simultaneous flow of water through the stern tube and the by-pass lines.

Therefore, limited water flow in the propeller shaft stern tube was probable cause of the sudden seizure and wear of the three bearings.

The alarm system did not alert the crew that the bearings of the propeller shaft were not being adequately lubricated, because the water flow sensor was installed in front of the fork splitting the installation into the stern tube and by-pass lines.

In the case described by Młynarczak, it is most likely that the limited water flow through the propeller shaft stern tube led to an increase in the temperature of the bearings, as the water flowing through the bearings was not eliminating the heat generated in the friction zone sufficiently quickly.
An increase in temperature reduces clearance between the polymer bush and the steel journal, since the polymer bush and the journal, increases its volume. At raised temperatures polymer bushes demonstrate greater thermal expansion and increased water absorption. This results in fast increase in the bush volume towards the shaft, since the bush is limited by housing from the outside. The steel shaft has higher thermal conductivity than the polymer bush. Therefore, the shaft conducts more heat than the bushing, and the shaft expands toward the bush [18].

When the bearing and the shaft are not capable of transferring out the heat from the friction zone, local contact between the surfaces of the bush and the journal occurs. If water flow is not resumed, seizure and rapid wear of the bush along its entire length occurs [19]. An example of a damaged polymer bush due to limited lubricating water flow is shown in Fig. 1.

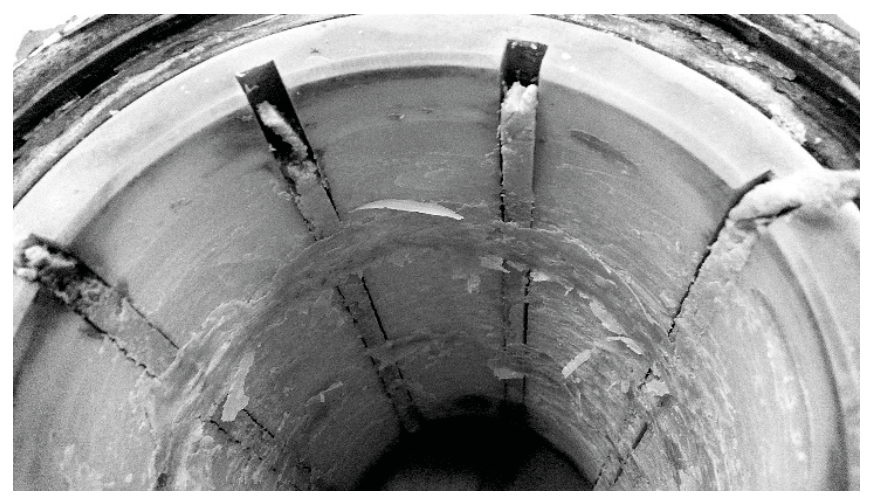

Fig. 1. Elastomer bush melted during the laboratory test. Test conditions: load: $0.2 \mathrm{MPa}$, speed $10 \mathrm{rev} / \mathrm{s}$, water flow $0 \mathrm{~L} / \mathrm{min}$.

Therefore, selecting the proper diameter clearance and material of the bush is a vital aspect in the design of waterlubricated bearings, allowing the bush, i.a., to continue operating failure-free under conditions of a temporary lack or decrease of water flow through the bearing.

\section{ORIGIN AND PURPOSE}

From a practical standpoint, it is important to ensure that the bearing suffering from lubrication system failure is able to continue working for some period of time without excessive wear of the bush, until the failure is eliminated by the ship's crew or power plant employees.

Water-lubricated bearings have been a subject of abundant research thanks to which their reliability and durability have increased. The research conducted on various materials and material additives has resulted in improving the tribological properties of bearings working under mixed-lubrication regime [20-25]. Some other research works have proven a strong influence of polymer bush material's elastic modulus on water-lubricated bearings' load-carrying capacity [26-28].

Many researchers have conducted numerical analyses and experimental research aimed at determining the impact of the placement and quantity of lubrication grooves on the 
hydrodynamic properties of bearings [29-35]. Thanks to such investigations, the heat generated in the friction zone may be efficiently carried off by water while maintaining the hydrodynamic load capacity of the bearings.

Analyses of real-life failures of polymer bush bearings are rarely the subject of scientific publications. The works by Hirani et al. [36] and Młynarczak [17] are exceptional in that respect. More common are failure analyses of white metal bearings such as in [37-42]. This stems from the fact that hydrodynamic bearings with white metal facing have been widely employed in the industry for many years. On the other hand, polymer bush bearings have been in use for just a few decades [19], and remain less popular due to their much lower hydrodynamic load capacity in comparison to white metal bearings.

The causes of thermal bush seizures are the subject of analyses conducted by some research centres $[18,43,44]$. They assess, among others, the impact of the polymer bush's thermal expansion on the bearing's diameter clearance. Takabi et al. [39] indicates that the faster the revolution speed of the shaft, the higher the probability of bush seizure due to overheating. Pap B. et al. [18] point out that, as a result of decreasing the bearing diameter clearance, a drop occurs in the flow of lubricating agent through the bearing, in consequence leading to a rise of temperature inside the bearing.

As indicated by Bishop et al. [19], once the process of bush seizure occurs, it advances very rapidly.

Experimental research carried out at the Technical University of Gdansk demonstrated that a certain group of water-lubricated bearings continues to function properly for a period of at least 2 hours despite the lack of water flow [45]. This group of bearings includes a three-layer bearing (PTFE - NBR - brass), in which the temperature after $2 \mathrm{~h}$ of continuous operation at the rotational speed of $11 \mathrm{rev} / \mathrm{s}$ and average loads between $0.2 \sim 0.6 \mathrm{MPa}$ did not exceed $50^{\circ} \mathrm{C}$.

During experimental research of elastic polymer and composite bushes [45], the bearings' temperature increased rapidly and a sudden stop of the test rig shaft occurred due to torque overload. The test rig shaft was stopped in both cases due to the bush seizure on the shaft, which resulted from the high thermal expansion and water absorption coefficients of the bushes.

Comparing the results of tests of elastic polymer and composite bushes with a three-layer bush, it may be concluded that the thermal resistivity of the bush (its conductivity, thickness, number of layers) may have a significant impact on the bearing's operation under the limited lubricating water flow. In other words, the bush, due to its low or high thermal resistivity, may play a significant role in transferring out the heat from the friction zone during failure of the lubrication system [46].

\section{SCOPE OF WORK}

The aim of this paper is to determine the degree of load to which an elastic polymer bush bearing may be exposed under the conditions of no-water flow, as well as to determine the limit values of flow intensity, at which an elastomer bush bearing continues to work properly for a period of at least $60 \mathrm{~min}$. A working temperature of $50^{\circ} \mathrm{C}$ and no signs of abrupt increase in motion resistance were set as the criteria for proper bearing operation.

Analysing literature and regulations, the author did not note any recommendations regarding the time how long the bearings of propeller shafts should continue working without excessive wear in case of lubrication system breakdown. In the author's opinion nature of the tests (bearings working under limited lubrication) is unusual and in marine industry is not propagated yet. Zander N. [47] from the U.S. Army Research Laboratory indicates that U.S. Army requires $30 \mathrm{~min}$ of operation of rotorcrafts following loss of lubrication. Time of 60 min was estimated by the author assuming that this 60 min should be enough for the crew of the ship to verify the problem and repair the lubrication system.

\section{TESTED BEARING}

The bearing subjected to tests under conditions of limited water flow had an elastic polymer bush with five lubricating grooves in its upper part. The material of the bush is approved by classification societies for use on ships (in bushes of propeller shaft bearings). Due to bush damage following the first series of tests (Fig. 1, Table 2), two new bushes of the same geometry and run-in methods were used. The dimensions and basic properties of the bushes are presented in Tab. 1 Bearing dimensions and bush properties.

\section{TEST RIG}

A new built test-rig made it possible to investigate realscale bearings with a shaft diameter of $100 \mathrm{~mm}$ at high power propulsion (Fig. 2). The test rig's shaft is made of chromiumnickel steel EN 1.4310 with roughness $\mathrm{Ra} 0.32 \mu \mathrm{m}$ as it is required in marine propeller shafts. The test rig is equipped with a $220 \mathrm{~kW}$ electric motor, with the maximum rotational speed of $1100 \mathrm{rev} / \mathrm{min}$ and nominal torque of $2600 \mathrm{Nm}$. Thus, the simulated conditions resemble those present on a small ship where the transmitted power is high enough to destroy the bearing.

Tab. 1 Bearing dimensions and bush properties

\begin{tabular}{|c|c|c|c|c|c|c|c|c|}
\hline $\begin{array}{l}\text { Bearing diameter / bearing } \\
\text { length / bush wall thickness } \\
{[\mathrm{mm}]}\end{array}$ & $\begin{array}{c}\text { Bearing's } \\
\text { radial clearance } \\
{[\mathrm{mm}]} \\
\end{array}$ & $\begin{array}{c}\text { Maximum } \\
\text { operating } \\
\text { temperature }\left[{ }^{\circ} \mathrm{C}\right]\end{array}$ & $\begin{array}{c}\text { Minimum } \\
\text { water flow } \\
\text { [L/min] }\end{array}$ & $\begin{array}{c}\text { Modulus } \\
\text { of elasticity } \\
\text { [MPa] }\end{array}$ & $\begin{array}{c}\text { Thermal expansion } \\
@ 0<\mathrm{T}<30^{\circ} \mathrm{C} \\
{\left[\times 10^{-5} \mathrm{C}\right]}\end{array}$ & $\begin{array}{c}\text { Thermal expansion } \\
@ \mathrm{~T}>30^{\circ} \mathrm{C} \\
{\left[\mathrm{x} 10-5^{\circ} \mathrm{C}\right]}\end{array}$ & $\begin{array}{c}\text { Thermal } \\
\text { conductivity } \\
{[\mathrm{W} / \mathrm{mK}]}\end{array}$ & $\begin{array}{l}\text { Therma } \\
\text { capacity } \\
{[\mathrm{kJ} / \mathrm{kgK}}\end{array}$ \\
\hline $100 / 200 / 12$ & 0.3 & 60 & 15 & 600 & 15.1 & 21.1 & 0.25 & 1.5 \\
\hline
\end{tabular}




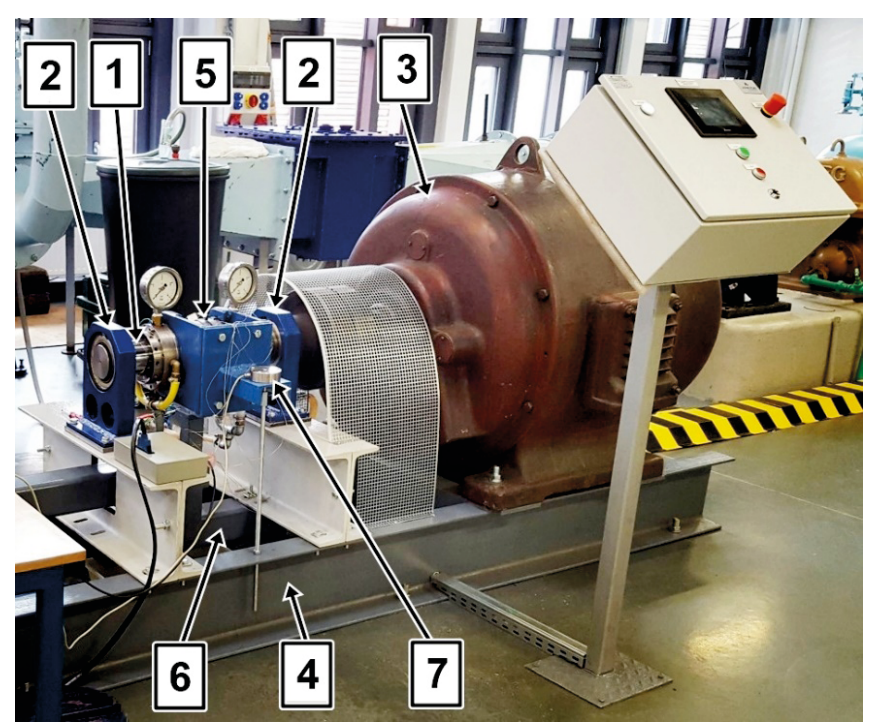

Fig. 2. High-power test rig, 1 - main shaft, 2 - rolling bearing, 3 -electric motor $220 \mathrm{~kW}$, 4 - test rig frame, 5 - bearing unit, 6 - radial force application unit, 7 - force sensor for measuring moment of friction.
The test rig (Fig. 2) consists of a shaft $100 \mathrm{~mm}$ in diameter (1) supported by two self-aligning bearings (2) and driven by an electric motor (3). The motor and the rolling bearings were mounted on the test rig frame (4). The tested bearing unit (5) was placed on the shaft between the two rolling bearings. Loads were applied on the tested bearing using a lever (6) from which weight discs were suspended. Measurement of the friction torque was obtained through a force sensor (7), which was mounted on the bearing set using a clamp with an arm.

The tested bearing unit (Fig. 3. Tested bearing unit: 1 tested polymer bush, 2 - steel housing, 3 - covers with sealing, 4 - stainless steel main shaft, 5 - thermocouples (T0 T7), 6 - radial force application unit, 7 - arm and sensor for measuring moment of friction.) consists of the tested bush (1) which was installed in a steel housing using a thermocompression method (2), as well as two steel covers (3) with sealing.

Similarly to real-life systems, the axial water flow is forced by a pump, which pushes water into the bearing.

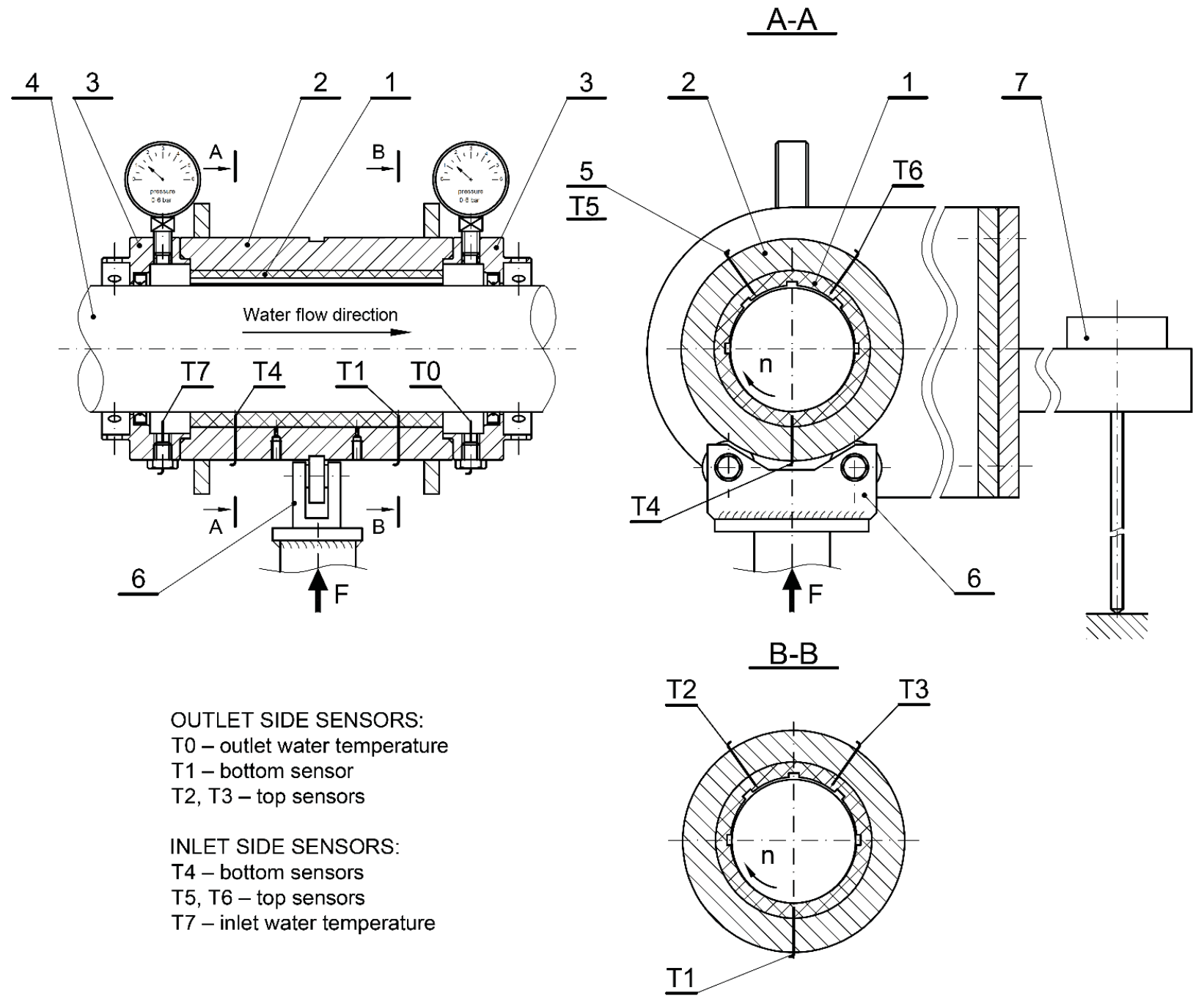

Fig. 3. Tested bearing unit: 1 - tested polymer bush, 2- steel housing, 3 - covers with sealing, 4 - stainless steel main shaft, 5 - thermocouples (T0 T7), 6 - radial force application unit, 7 - arm and sensor for measuring moment of friction. 
The water-pumping system includes a valve installed between the pump and the tested bearing, which allows to limit or stop the water flow through the bearing. To ensure that the bearing remains completely filled with water during the tests in conditions of no-water flow, the test rig was additionally equipped with a shut-off valve at the wateroutflow of the bearing.

The measured motion resistance is the sum of: resistance in the tested bearing (1), the sliding resistance of the sealing (3) on both sides of the bearing and the resistance of the rollers in the support system (6). In a hydrodynamic lubrication regime, the summarised measurement of motion resistance is subjected to significant error, as such a bearing creates very little resistance in relation to the other elements.

However, the motion resistance of the remaining elements may be considered to be of no significance, when a bearing operates under conditions of limited water flow. The bearing seizing on the shaft generates high motion resistance, making remaining motion resistance components negligible.

During the tests continuous measurement of the bearing temperature was conducted at eight measurement points (Fig. 3. Tested bearing unit: 1 - tested polymer bush, 2- steel housing, 3 - covers with sealing, 4 - stainless steel main shaft, 5 - thermocouples (T0 T7), 6 - radial force application unit, 7 - arm and sensor for measuring moment of friction., pos. 5). Two thermocouples (T0 and T7) were installed in the bearing covers (3) in order to provide constant water temperature monitoring at the inflow and outflow of the bearing. The remaining six (T1 T6) were placed in openings distributed radially along the bush circumference in two cross-sections: A-A - water inlet side (T4, T5, T6), B-B - water outlet side (T1, T2, T3). Two sensors (T1 and T4) were placed in the lower part of the bush, and the remaining ones (T2, T3, T5, T6) in the upper part between the lubrication grooves. The openings in the bearing, in which the temperature sensors were placed, were of a depth that allowed the thermocouple tip to be positioned $3 \mathrm{~mm}$ under the sliding surface of the bush. Type K thermocouples with an exposed junction of $\varnothing 0.8 \mathrm{~mm}$ in diameter were employed, allowing, in the opinion of the author, for relatively quick recording of sudden temperature changes, which is especially significant in recording dynamic temperature changes [48].

\section{EXPERIMENTAL PROCEDURE}

The manufacturer of the tested bearing recommends minimum water flow of $15 \mathrm{~L} / \mathrm{min}$ for the loaded bearing with nominal diameter of $100 \mathrm{~mm}$ (Tab. 1 Bearing dimensions and bush properties). Water flowing with that rate effectively transfers the heat from the friction zone, which is of key importance, since the propeller shaft bearing is working at low shaft speeds and high loads (conditions of mixed lubrication).

It was decided that the bearing would be tested in the water flow range of $12 \mathrm{~L} / \mathrm{min}$ to $0 \mathrm{~L} / \mathrm{min}$ at three different loads, representing the average pressures of: $0.2,0.3$ and 0.4 $\mathrm{MPa}$ at a constant shaft revolution speed of $10 \mathrm{rev} / \mathrm{s}$ (Table
2). Pressure values of $0.4 \mathrm{MPa}$ are representative of average, typical stern tube bearing pressures of a ship propeller shaft.

Prior to commencing tests, the bearings were subjected to an identical water absorption process through submersion in a container and run-in. The bushes were run-in within a range of variable speeds and loads, thanks to which the surfaces of both bushes were smoothed out, just as is the case with bearings operating on real-life objects.

Two bearings with the same geometry and run-in methods were used. The first bush was subjected to eight tests at the load of 0.2 MPa (Table 2). Each of these tests represented a different water flow value. The tests were carried from day to day, so that each consecutive test would start in the same conditions (thermocouples indicating ambient temperature).

Due to damaging the first bush during testing in the conditions of $0.2 \mathrm{MPa}$ and no-water flow $(0 \mathrm{~L} / \mathrm{min})$, the second bush was used in further testing ( $0.3 \mathrm{MPa}$ and $0.4 \mathrm{MPa})$. Since the tests were carried out in such a way as not to damage the bush, the second bush was tested in a range of different flow intensities at the pressures of $0.3 \mathrm{MPa}$ and $0.4 \mathrm{MPa}$.

Tab. 2 Conditions of bearing tests

\begin{tabular}{|c|c|c|c|}
\hline \multirow{2}{*}{ Test no. } & Bearing no. 1 & \multicolumn{2}{|c|}{ Bearing no. 2 } \\
\cline { 2 - 4 } & $0.2 \mathrm{MPa}$ & $0.3 \mathrm{MPa}$ & $0.4 \mathrm{MPa}$ \\
\cline { 2 - 4 } & \multicolumn{3}{|c|}{ Water flow $[1 / \mathrm{min}]$} \\
\hline 1 & 11.5 & - & 12 \\
\hline 2 & 9.3 & - & - \\
\hline 3 & 5.25 & - & - \\
\hline 4 & 4 & 4.8 & - \\
\hline 5 & 3 & 2.5 & 2.2 \\
\hline 6 & 2 & 1 & 0.9 \\
\hline 7 & 1 & 0.5 & 0 \\
\hline 8 & 0 & 0 & - \\
\hline
\end{tabular}

Each test commenced in the same way: the valves in front of and behind the bush were opened and a centrifugal pump was activated, propelling water from a $200 \mathrm{~L}$ container to the bearings. The initial water flow amounted to $15 \mathrm{~L} / \mathrm{min}$. Subsequently, the bearing set was vented, in order to make certain that the bearing was completely filled with water. The electric motor was turned on with the shaft revolution speed set at $10 \mathrm{rev} / \mathrm{s}$. Next, a sufficient number of disc weights were suspended to obtain the average pressures of $0.2,0.3$ or $0.4 \mathrm{MPa}$. During the tests the load remained unchanged. Using the valve located in front of the inlet channel of the bearing, the flow of water was decreased to the values presented in the Table 2 . In the case of tests conducted under the conditions of no-water flow, the valve located behind the bearing was closed to prevent free outflow of water from the bearing. The actual testing started from that moment. During testing it was possible to maintain constant measurement of the temperature and torque. The water flow intensity was controlled every few minutes.

It was decided that the test would last a minimum of 60 minutes or would be terminated earlier if any of the thermocouples measuring the temperature of the water or 
the bearing indicated a temperature higher than $50^{\circ} \mathrm{C}$, or if an alarming increase in the levels of motion resistance was observed.

\section{RESULTS \& DISCUSSION}

During each test, the heat generated inside the bearing was partially transferred by the flowing water, as well as by the shaft and the bearing housing to the surroundings, i.e., the air. During the tests, the temperature in the laboratory hall varied from 21 to $24^{\circ} \mathrm{C}$. In order to compare the impact of the limited water flow on the change of the temperature inside the bearing, the increase in temperature during the bearing's operation is presented.

It should be underlined that the heat dissipation conditions inside the lab were more demanding than those found on a ship, where the shaft tube is indirectly surrounded by water whose temperature is often lower than $18^{\circ} \mathrm{C}$.

\section{SPECIFIC PRESSURE OF 0.2 MPA}

The temperature increase during the operation of the bearing at the load of $0.2 \mathrm{MPa}$ is presented in Fig. 4 and Fig. 5 .

Fig. 4 presents the temperature increase for the bearing operating at the water flow of 11.5 to $1.2 \mathrm{~L} / \mathrm{min}$ and Fig. 5 presents the results for the bearing operating at the no-water flow condition.

During the operation of the bearing at the water flow intensity of 11.5 to $1.2 \mathrm{~L} / \mathrm{min}$, no sudden changes in motion resistance levels were observed, and each of the eight temperature sensors indicated the same rise in temperature. Therefore, the indications of only one sensor are presented and the level of friction torque is omitted (Fig. 4).

It may be noticed in Fig. 4 that the maximum temperature increase was recorded for the water flow of $1.2 \mathrm{~L} / \mathrm{min}$, amounting to $5^{\circ} \mathrm{C}$ after 60 minutes of bearing operation. Additionally it can be observed that the temperatures inside the bearing are stabilising and the bearing unit is moving towards thermal equilibrium.

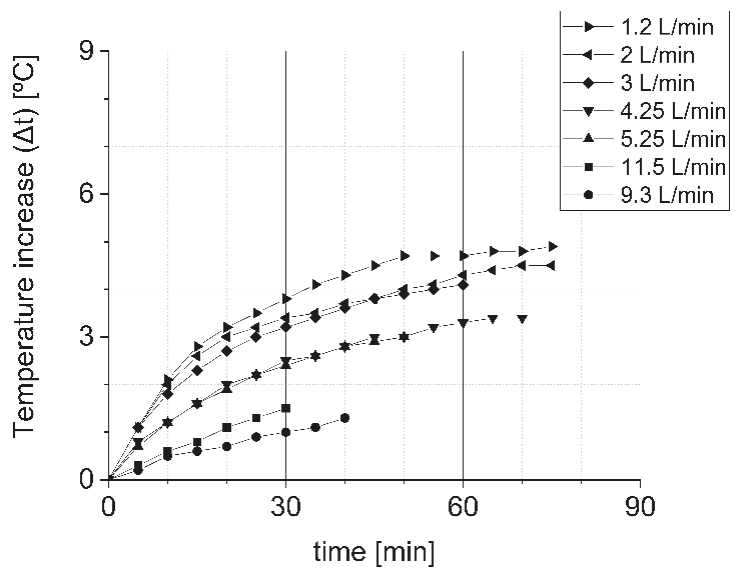

Fig. 4. Temperature increase diagram for bearing with elastic polymer bush. Test conditions: pressure $=0.2 \mathrm{MPa}$, shaft revolution speed $=10 \mathrm{rev} / \mathrm{s}$, water flow $=1.2 \sim 11.5 \mathrm{~L} / \mathrm{min}$.
It would be expected that as the water flow through the bearing increases, the temperature in the bearing decreases. However, in this study, the temperature increase was larger when the water flow was 11.5 than $9.3 \mathrm{~L} / \mathrm{min}$. The reason was the fact that the ambient temperature during the test at the water flow $11.5 \mathrm{~L} / \mathrm{min}$ was $3^{\circ} \mathrm{C}$ higher than during the remaining tests. This ambient temperature difference played an important role, because the cooling water in the tank had the same temperature as the surroundings.

During the test conducted at the load of $0.2 \mathrm{MPa}$ and no-water flow, bush damage due to overheating took place (Fig. 5). The presumption of the author was to terminate the test if the temperature in the bearing exceeded $50^{\circ} \mathrm{C}$, meaning a temperature increase not greater than $30^{\circ} \mathrm{C}$ or if a concerning increase in the motion resistance was observed. The results of that test are presented in Fig. 5.
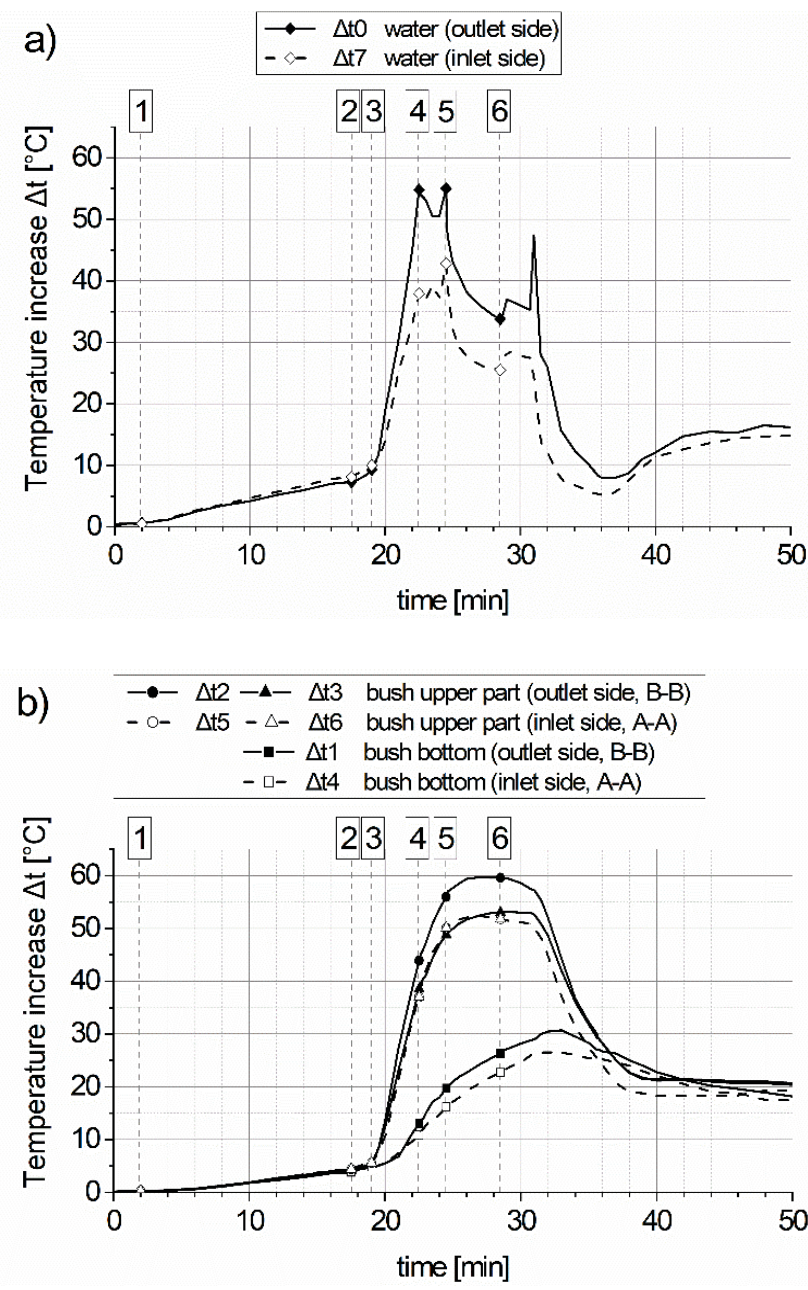


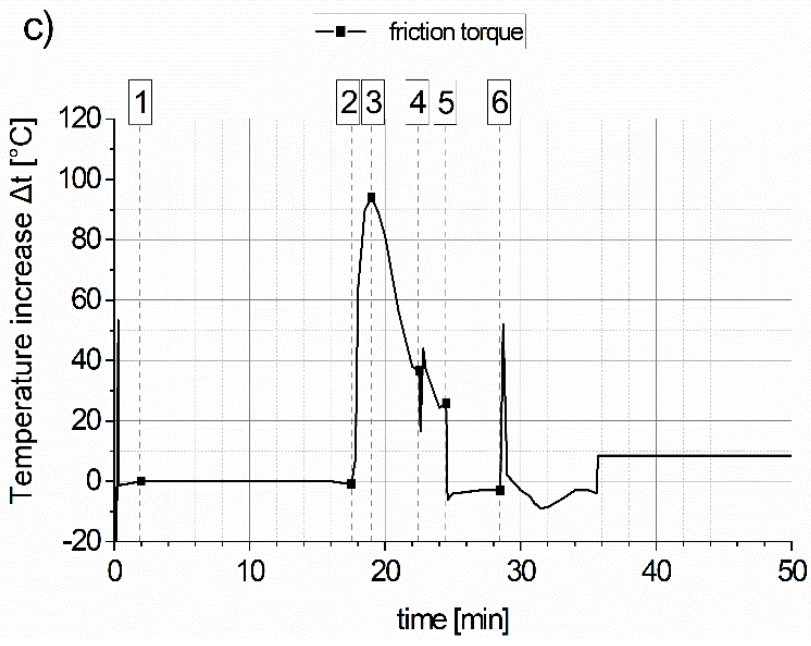

Fig. 5. Temperature and friction torque increase diagrams for bearing with elastic polymer bush. Test conditions: pressure $=0.2 \mathrm{MPa}$, shaft revolution speed $=10 \mathrm{rev} / \mathrm{s}$, water flow $=0 \mathrm{~L} / \mathrm{min}$. a) Water temperature increase diagram, b) Bush temperature increase diagram, c) Friction torque increase diagram,

1 - turning off the water flow, 2 - sudden increase in motion resistance,

3 - limiting shaft revolution speed to $100 \mathrm{rev} / \mathrm{s}$ and attempting to turn on the water flow, 4 - another attempt to turn on the water flow, 5 - stopping electric motor, 6 - momentary activation of the electric motor.

The process of simulating a malfunction was initiated by closing off the water flow through the bearing (1). Shutting off the water flow (1) resulted in a temperature increase of the water and the bush. The water temperatures on the inlet and outlet sides of the bearing were increasing at the same rate, and from the moment of closing the valve they were slightly higher than the bush temperatures (measured $3 \mathrm{~mm}$ underneath the sliding surface).

When motion resistance had increased (2), the author decided to continue testing, since the water temperature increased by only $8^{\circ} \mathrm{C}$ from the simulation start and did not exceed assumed $30^{\circ} \mathrm{C}$. In less than two minutes temperature differentiation in the bearing was observed (3) and at this moment the valves were opened, the pump transporting water to the bearing was activated, and the revolution speed of the motor reduced from 10 to $1.7 \mathrm{rev} / \mathrm{s}$ (100 rev/min). The motion resistance started to decrease, but unfortunately no-water flow through the bush was observed and the bush and the water temperatures were increasing at a very rapid pace (segment 3-4).

According to the author, the flow of water through the bearing was impossible (3), since there was no clearance between the bush and the journal, and the lubrication grooves were blocked by the melted polymer. Additionally, inlet water temperature sensor did not indicate any inflow of fresh water (lack of temperature drop). Water flow was observed after second attempt at activation of the pump (4), resulting in a momentary drop of the water temperatures. The electric motor was turned off at (5) and turned on for a moment at (6).

After disassembling the bearing's covers, the melted bush was visible on both sides of the bearing (Fig. 6).

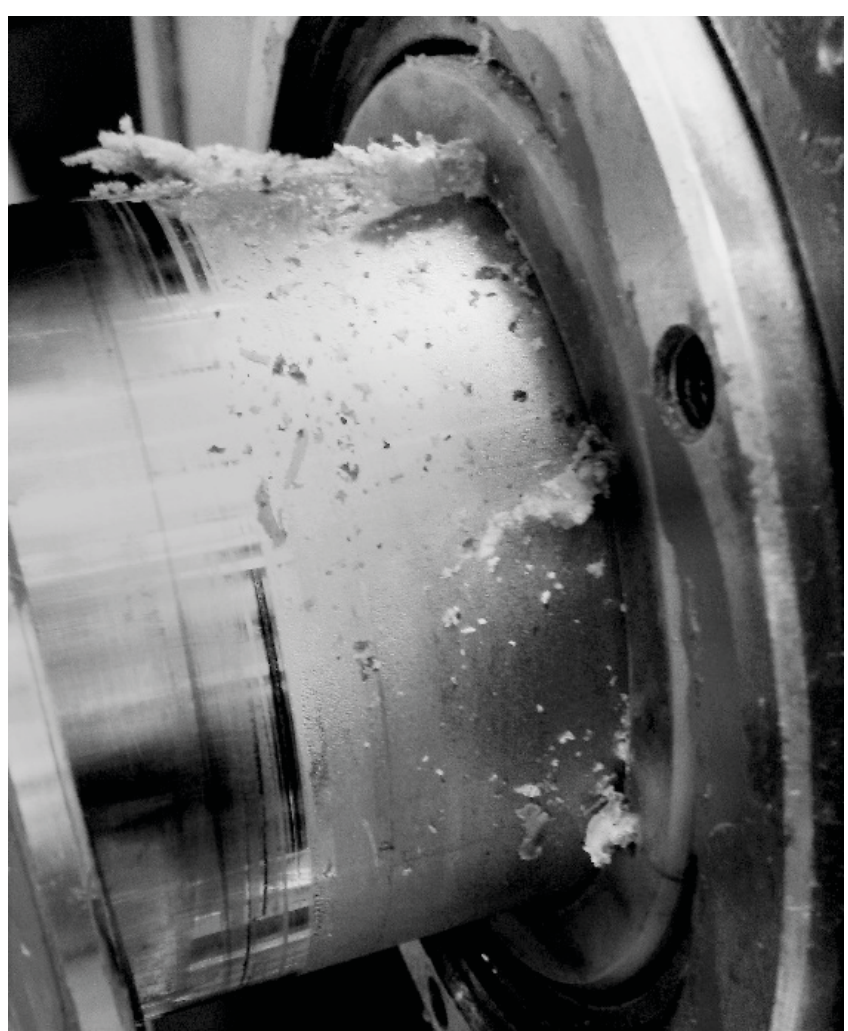

Fig. 6. Disassembly of bearing's cover: lubricating grooves clogged with wear particles. Test conditions: pressure $=0.2 \mathrm{MPa}$, shaft revolution speed $=10 \mathrm{rev} / \mathrm{s}$, water flow $=0 \mathrm{~L} / \mathrm{min}$.

\section{SPECIFIC PRESSURE OF 0.3 MPA}

It was decided to start the test for the load of $0.3 \mathrm{MPa}$ at the water flow intensity of approx. $5 \mathrm{~L} / \mathrm{min}$ (Fig. 7), assuming that at higher intensities the bearing will continue to operate properly for a period of 60 minutes, since the temperature and motion resistance values did not cause concern at low loads $(0.2 \mathrm{MPa})$ and the water flows above zero (Fig. 4).

During the operation of the bearing at the water flow intensity of 4.8 to $0.5 \mathrm{~L} / \mathrm{min}$ and load of $0.3 \mathrm{MPa}$, no sudden changes in motion resistance levels were observed, and each of the eight temperature sensors indicated the same rise in temperature. Therefore, the indications of only one sensor are presented and the level of friction torque is omitted (Fig. 7).

Similarly to the test results for the loads of $0.2 \mathrm{MPa}$, the temperatures inside the bearing are stabilising and the bearing unit is moving towards thermal equilibrium. The maximum temperature increase was recorded for the water flow of $0.5 \mathrm{~L} /$ min, amounting to $8^{\circ} \mathrm{C}$ after 60 minutes of bearing operation. 


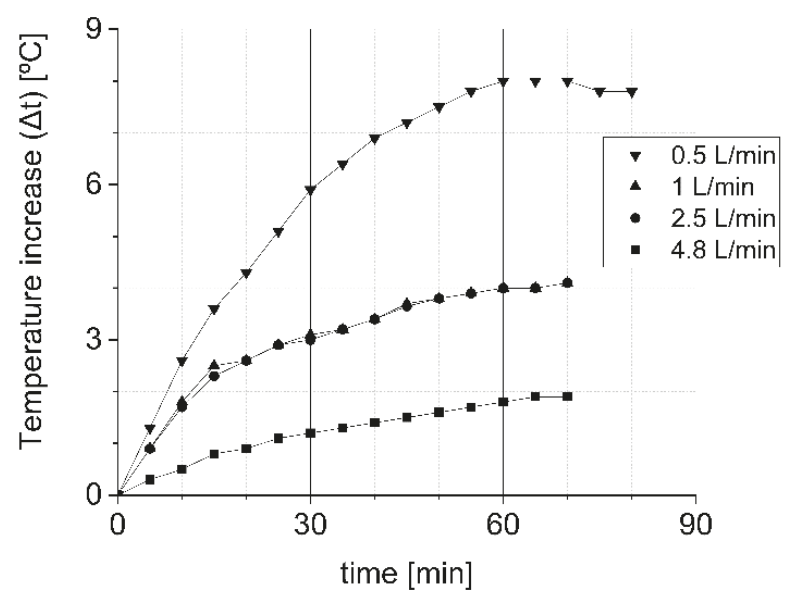

Fig. 7. Temperature increase diagram for bearing with elastic polymer bush. Test conditions: pressure $=0.3 \mathrm{MPa}$, shaft revolution speed $=10 \mathrm{rev} / \mathrm{s}$, water flow $=0.5 \sim 4.8 \mathrm{~L} / \mathrm{min}$.

To avoid sudden damage of the bush during the test conducted at $0.3 \mathrm{MPa}$ and no-water flow, it was decided to proceed in the following manner:

- If a sudden increase in the resistance of motion is observed, the immediate action is to activate the water pump at the setting of approx. $15 \mathrm{~L} / \mathrm{min}$.

- If the water cooling proves insufficient, as the second step the electric motor is to be turned off.

The results of the test conducted at $0.3 \mathrm{MPa}$ in the conditions of no-water flow are presented in Fig. 8.

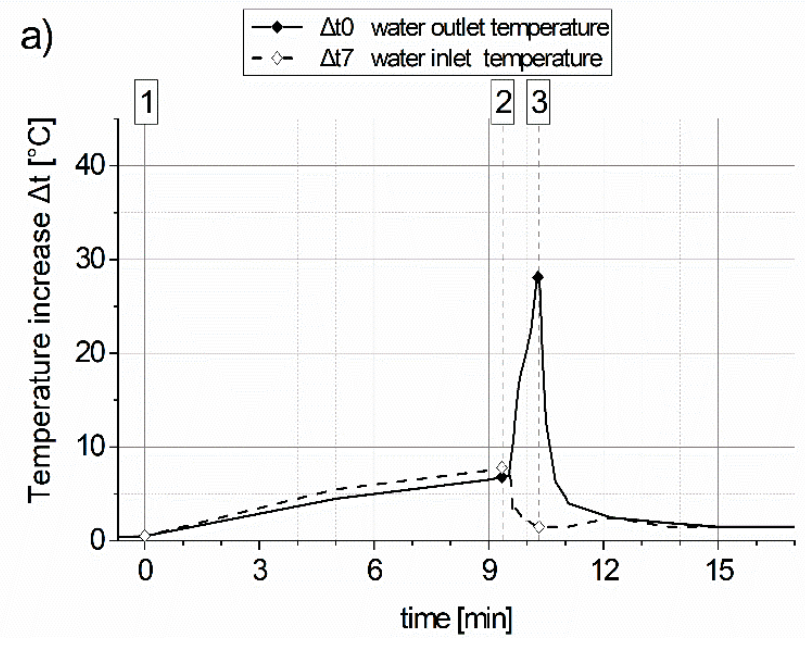

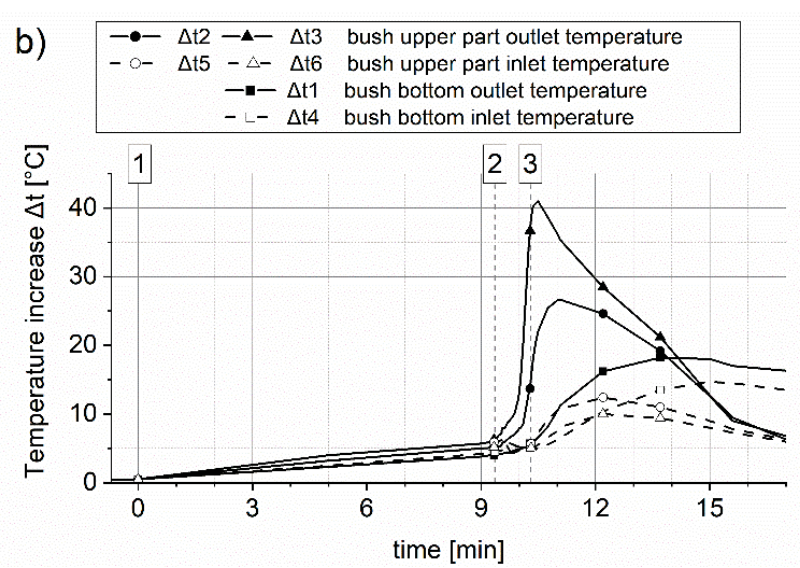
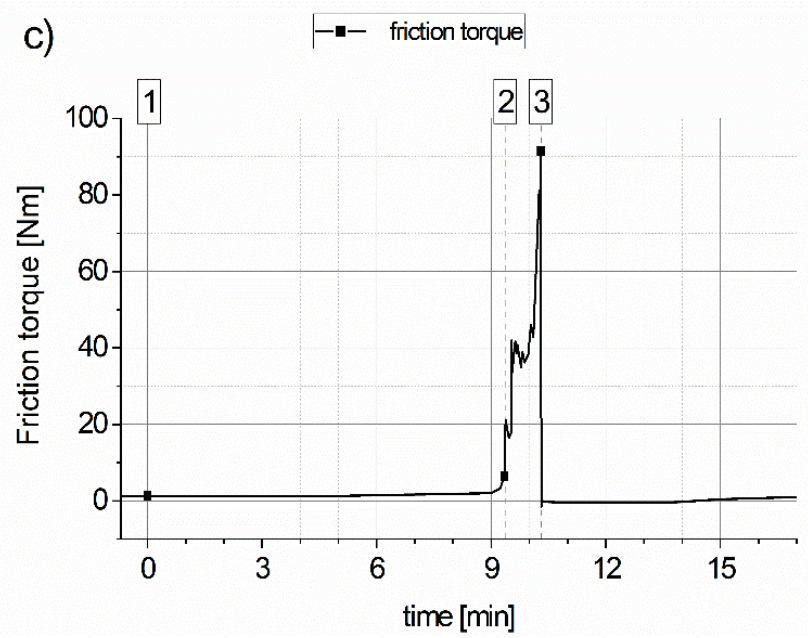

Fig. 8. Temperature and friction torque increase diagrams for bearing with elastic polymer bush. Test conditions: pressure $=0.3 \mathrm{MPa}$, shaft revolution speed $=10 \mathrm{rev} / \mathrm{s}$, water flow $=0 \mathrm{~L} / \mathrm{min}$. a) Water temperature increase diagram b) Bush temperature increase diagram, c) Friction torque increase diagram, 1 - closing the water flow, 2 - sudden increase in the resistance of motion, 3 stopping motor's operation.

Following the closing of the water flow (1), the temperatures of the water and the bush rise at a similar rate. After approx. 9 minutes into the test, a sudden rise in the resistance of motion occurs (2), thus the valves are being opened and the water pump turned on. This resulted in bringing down the temperatures on the inlet side of the bearing $(\Delta t 5, \Delta t 6, \Delta t 7)$, but also in a sudden increase of the temperatures at the outlet $(\Delta t 0, \Delta t 2, \Delta t 3)$. These temperature changes concerns the water and the upper part of the bearing, where lubricating grooves are placed. The outlet temperatures increase is a result of pushing out the hot water from the bearing and it might be additionally affected by water backflow phenomenon [49]. The opening of the fresh water flow did not affect the temperatures at the bottom of the bush $(\Delta \mathrm{t} 1, \Delta \mathrm{t} 4)$, since water mainly flowed through the lubrication grooves.

As the friction torque was still increasing, it was decided to turn off the motor shaft (2). The stopping of the shaft resulted in immediate drop of the outlet water temperature and delayed drop of the bush temperatures. 
Disassembly of both covers revealed a small amount of polymer bush wear particles located on the shaft and lack of any wear particles clogging the lubrication grooves.

\section{SPECIFIC PRESSURE OF 0.4 MPA}

Taking into account that the radial clearance of the bearing might have been altered in the previous tests, it was decided to verify whether the bearing would be able to work at the load of $0.4 \mathrm{MPa}$ and a flow of $12 \mathrm{~L} / \mathrm{min}$ (Fig. 9). As it turned out, the bearing was able to operate for the set period of time $(60 \mathrm{~min})$ without an excessive temperature increase $\left(2^{\circ} \mathrm{C}\right)$. Moreover, the bearing underwent further tests at 2.2 and $0.9 \mathrm{~L} / \mathrm{min}$, during which neither sudden changes in the resistance of motion nor large temperature increases were observed for the period of 60 minutes.

The fact is that the temperatures were no longer increasing in a degressive way, which may be symptomatic of temperature instability in the system and the occurrence of mixed friction in the bearing.

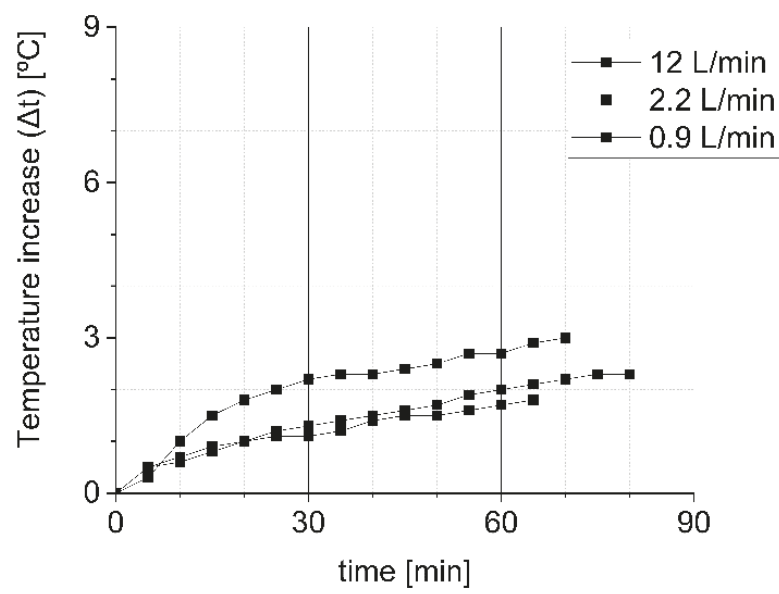

Fig. 9. Temperature increase diagram for bearing with elastic polymer bush Test conditions: pressure $=0.4 \mathrm{MPa}$, shaft revolution speed $=10 \mathrm{rev} / \mathrm{s}$, water flow $=0.9 \sim 12 \mathrm{~L} / \mathrm{min}$.

The final test consisted of investigating the bearing's behaviour at loads of $0.4 \mathrm{MPa}$ and conditions of no-water flow (Fig. 10).

From the moment of closing the water flow through the bearing (1) the water temperature was growing faster than the bearing temperature. After 30 minutes of the bearing's operation at $0.4 \mathrm{MPa}$ sudden increase in the resistance of motion was observed (2). At this point, the valves were opened and the water pump was turned on. Just a few seconds later the cover sealing was pushed out (on the outlet side) by steaming water (2). The steaming water began to leak out and, despite activating the pump, no-water flow through the bearing was observed. A moment later the motor was turned off (3). After switching the electric motor off, several attempts were made to activate the water pump $(4,5)$. It was only after about 30 minutes from the moment of pushing the sealing out that the water flow through the bearing finally took place (6).
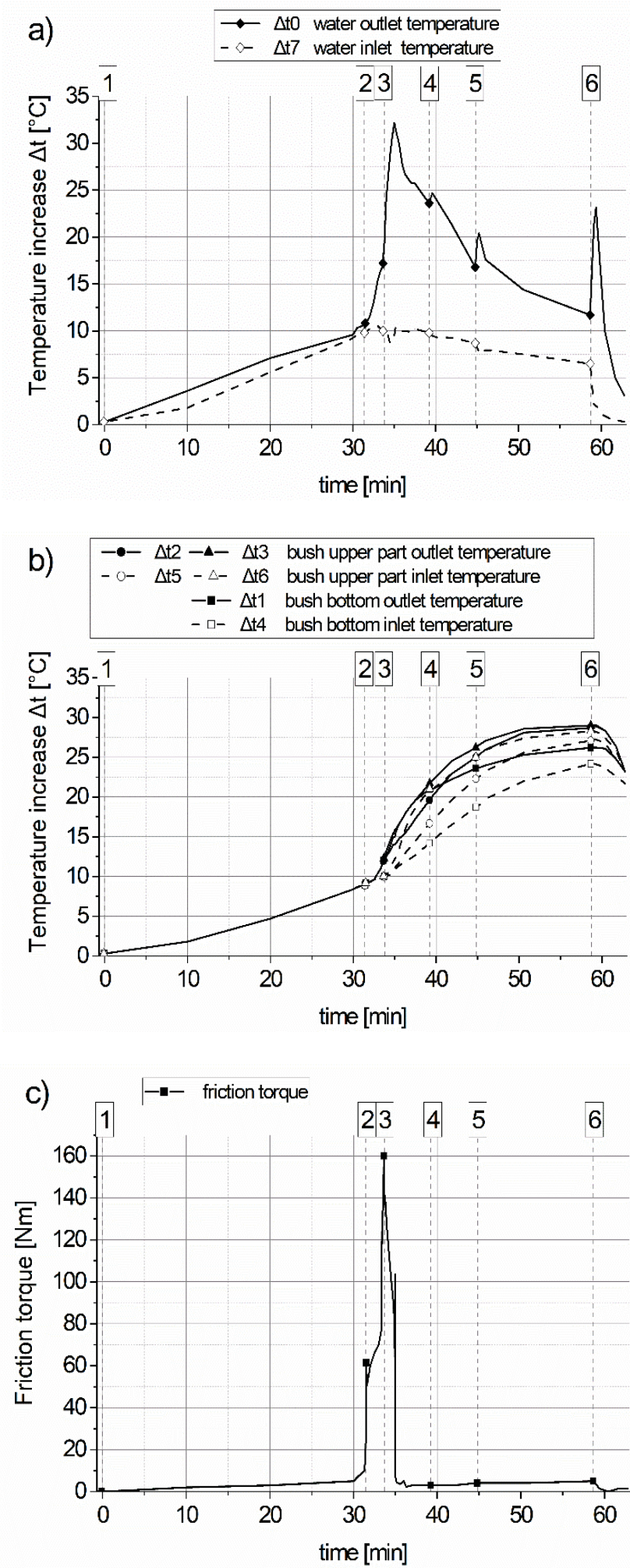

Fig. 10. Temperature and friction torque increase diagrams for bearing with elastic polymer bush. Test conditions: pressure $=0.4 \mathrm{MPa}$, shaft revolution speed $=10 \mathrm{rev} / \mathrm{s}$, water flow $=0 \mathrm{~L} / \mathrm{min}$. a) Water temperature increase diagram,

b) Bush temperature increase diagram, c) Friction torque increase diagram, 1 - closing the water flow, 2 - sudden increase in the resistance of motion, turning the pump on, pushing out of the cover sealing by steaming water,

3 -stopping the motor, 4, 5, 6-attempts at turning the water flow on. 
The test demonstrates that the temperature of the water inside the bearing must have been $100^{\circ} \mathrm{C}$, despite the fact that the outlet water temperature sensor indicated only $33^{\circ} \mathrm{C}$ just a moment before the sealing was pushed out.

\section{SUMMARY}

Experimental study of the bearing with elastomer bush showed that the axial water flow plays a significant role in heat transferring out from the bearing. The real-scale stern-tube bearing with $100 \mathrm{~mm}$ nominal diameter is able to operate properly for a period of at least 60 minutes at the constant loads, shaft speed and marginal water flows, limited even to $0.5 \mathrm{~L} / \mathrm{min}$. The bearing in the absence of the water flow (fully filled with water) was able to work properly for short periods (15-30 minutes) followed by rapidly advancing seizure of the bearing and its damage. The process of bearing's damage can be stopped by activating the maximum water flow and decreasing the shaft's revolution speed to zero.

Practically, it is very difficult to capture the moment when the failure occurs, since the seizure is preceded only by the appearance of a sudden increase of bearing motion resistance. Additionally, during the seizure of the tested bearing, the power consumption of the electric motor increased from 3 to only $25 \mathrm{~kW}$. It should be underlined that the seizure of the bearing with polymer bush in comparison to the bearings with white-metal facing is frequently connected to melting of the bush material due to temperatures exceeding the melting point of the polymer. This confirms reports from ship crews of similar failures occurring, without increases in the engine loads being observed when the failure took place.

The tested bearing was able to work properly for established time at marginal water flows, but probably not without any wear. Both tested bushes had undergone melting and hydrolysis (Fig. 1). The deep cracks in the sliding surface, characteristic of the hydrolysis process, indicates that the bushes had been subjected to the long-term exposure to water at a temperature of at least $50^{\circ} \mathrm{C}$. Thus, the process of hydrolytic degradation of the bushes could have already occurred during tests at the water flows greater than $0 \mathrm{~L} / \mathrm{min}$.

In the conditions of limited water flow, the water temperature measurements at the bearing's inlet and outlet may be affected by a large error, since a large part of heat remains inside the bearing. When the lubricant flow is completely shut-down, sensors located in front of and behind the bearing indicate the temperature of the water, which is barely affected by the heat generated in friction zone. Therefore, installing sensors at the inlet and / or outlet of the stern tube may not provide information about possible overheating of the aft bearing.

Theoretical studies should be carried out to see if experimentally tested bearing in conditions of limited water flow is working under hydrodynamic or mixed lubrication regime. Additionally, it would be worth paying attention to the thermal resistivity of the polymer bushes. This could explain why the tested bearing with elastomeric bush is not capable of working in no-water flow conditions and the bearing with three-layer bush is [45].

\section{ACKNOWLEDGEMENTS}

This work was a part of research grant no. 2016/23/B/ ST8/03104 entitled "Research on water-lubricated sliding couples in unfavourable operating conditions" financed by the Polish National Science Centre.

\section{REFERENCES}

1. Ogle KJ, Carter CD. Converting an icebreaker from an oil lubricated stern tube bearing system to a seawater lubricated stern tube bearing considering environmental and operating costs. Int. Conf. Exhib. Perform. Ships Struct. Ice 2010, ICETECH 2010, 2010, p. 141-5.

2. Richard C, Groves S. An Oil to Water Conversion of a Hydro Turbine Main Guide Bearing - Technical and Environmental Aspects. Thordon Bear Newsworks 20042 2004:1-11. https://thordonbearings.com/docs/defaultsource/hydro-power/technical-papers/technical-paper--oil-to-water-conversion-of-a-hydro-turbine-main-guidebearing.pdf?sfvrsn=9f11eb91_8 (accessed April 22, 2020).

3. Auger G, Eng P. Reducing Maintenance with Water Lubricated Turbine Guide Bearings - Design Principles \& Case Studies. Tribodays 2017.

4. Roldo L, Komar I, Vulić N. Design and Materials Selection for Environmental Friendly Ship Propulsion System. J Mech Eng 2013;1:25-31.

5. Thordon Bearings Inc. Stern Tube Conversions Reduce Pollution Risk. Thordon Bear INC Mar Issue 2012;1. https://thordonbearings.com/docs/default-source/marine/ references/stern-tube-conversions-reduce-pollution-risk. pdf?sfvrsn=bb7e9998_8 (accessed April 22, 2020).

6. Oil to water conversions | Convert your seal to water lubrication. Wartsila 2013. https://www.wartsila.com/ docs/default-source/Service-catalogue-files/SealsBearings-services/stern-tube-conversions---oil-to-water. pdf?sfvrsn=0 (accessed April 22, 2020).

7. DuraBlue Composite Water-Lubricated Stern Tube Bearings. Duramax Mar 2018. http://www.duramaxmarine. com/pdf/DuraBlue-Bearing_broch2019.pdf (accessed April 22, 2020).

8. Litwin W. Water-lubricated bearings of ship propeller shafts - problems, experimental tests and theoretical investigations. Polish Marit Res 2009;16. https://doi. org/10.2478/v10012-008-0055-z. 
9. L. Shaft line alignment analysis taking ship construction flexibility and deformations into consideration. Mar Struct 2005;18:62-84. https://doi.org/10.1016/J. MARSTRUC.2005.05.002.

10. Bouyer J, Fillon M. An Experimental Analysis of Misalignment Effects on Hydrodynamic Plain Journal Bearing Performances. J Tribol 2002;124:313. https://doi. org/10.1115/1.1402180.

11. Litwin W, Olszewski A, Wodtke M. Influence of Shaft Misalignment on Water Lubricated Turbine Sliding Bearings with Various Bush Modules of Elasticity. Key Eng Mater 2011;490:128-34. https://doi.org/10.4028/www. scientific.net/KEM.490.128.

12. Sun J, Changlin G. Hydrodynamic lubrication analysis of journal bearing considering misalignment caused by shaft deformation. Tribol Int 2004;37:841-8. https://doi. org/10.1016/j.triboint.2004.05.007.

13. Litwin W. Influence of main design parameters of ship propeller shaft water-lubricated bearings on their properties. Polish Marit Res 2010;17:39-45. https://doi. org/10.2478/v10012-010-0034-z.

14. Dong CL, Yuan CQ, Bai XQ, Yang Y, Yan XP. Study on wear behaviours for NBR/stainless steel under sand waterlubricated conditions. Wear 2015;332-333:1012-20. https:// doi.org/10.1016/J.WEAR.2015.01.009.

15. Ginzburg BM, Tochil'nikov DG, Bakhareva VE, Anisimov A V., Kireenko OF. Polymeric materials for water-lubricated plain bearings. Russ J Appl Chem 2006;79:695-706. https:// doi.org/10.1134/S1070427206050016.

16. Akchurin A, Bosman R, Lugt PM, van Drogen M. Analysis of Wear Particles Formed in Boundary-Lubricated Sliding Contacts. Tribol Lett 2016;63:1-14. https://doi.org/10.1007/ s11249-016-0701-z.

17. Młynarczak A. A case of bearings seizing in shaft pipe. Sci J Polish Nav Acad 2014;199:51-63. https:/doi. org/10.5604/0860889x.1139633.

18. Pap B, Fillon M, Guillemont M, Bauduin L, Chocron J, Gédin P, et al. Experimental and Numerical Analysis on the Seizure of a Carbon-Filled PTFE Central Groove Journal Bearing during Start-Up Period. Lubricants 2018;6:14. https://doi.org/10.3390/lubricants6010014.

19. Bishop JL, Ettles CMM. The seizure of journal bearings by thermoelastic mechanisms. Wear 1982;79:37-52. https:// doi.org/10.1016/0043-1648(82)90202-2.
20. McCarthy, D. M. C.; Glavatskih SB. Assessment of polymer composites for hydrodynamic journal-bearing applications. Lubr Sci 2009:123-34. https://doi.org/10.1002/ls.

21. Del Din M, Kassfeldt E. Wear characteristics with mixed lubrication conditions in a full scale journal bearing. Wear 1999;232:192-8. https://doi.org/10.1016/ S0043-1648(99)00145-3.

22. Chen S, Li J, Wei L, Jin Y, Shang H, Hua M, et al. Tribological properties of polyimide-modified UHMWPE for bushing materials of seawater lubricated sliding bearings. Tribol Int 2017;115:470-6. https://doi.org/10.1016/J. TRIBOINT.2017.06.011.

23. Chen B, Wang J, Yan F. Friction and Wear Behaviors of Several Polymers Sliding Against GCr15 and 316 Steel Under the Lubrication of Sea Water. Tribol Lett 2011;42:1725. https://doi.org/10.1007/s11249-010-9743-9.

24. Demirci MT, Düzcükoğlu H. Wear behaviors of Polytetrafluoroethylene and glass fiber reinforced Polyamide 66 journal bearings. Mater Des 2014;57:560-7. https://doi.org/10.1016/j.matdes.2014.01.013.

25. Wasilczuk M. Polymer lining in the design of hydrodynamic thrust bearings. Tribologia 2007;1:211-23.

26. Litwin W. Water Lubricated Marine Stern Tube Bearings: Attempt at Estimating Hydrodynamic Capacity. ASME/ STLE 2009 Int. Jt. Tribol. Conf., Memphis, Tennessee, USA: ASMEDC; 2009, p. 179-81. https://doi.org/10.1115/ IJTC2009-15068.

27. Linjamaa A, Lehtovaara A, Larsson R, Kallio M, Söchting S. Modelling and analysis of elastic and thermal deformations of a hybrid journal bearing. Tribol Int 2018;118:451-7. https://doi.org/10.1016/J.TRIBOINT.2017.02.029.

28. Kraker A, van Ostayen RAJ, Rixen DJ. Calculation of Stribeck curves for (water) lubricated journal bearings. Tribol Int 2007;40:459-69. https://doi.org/10.1016/j. triboint.2006.04.012.

29. Costa L, Fillon M, Miranda AS, Claro JCP. An experimental investigation of the effect of groove location and supply pressure on the THD performance of a steadily loaded journal bearing. J Tribol 2000;122.

30. Majumdar BC, Pai R, Hargreaves DJ. Analysis of waterlubricated journal bearings with multiple axial grooves. Proc Inst Mech Eng Part J J Eng Tribol 2004;218:135-46. https://doi.org/10.1177/135065010421800208.

31. Pai RS, Pai R. Stability of four-axial and six-axial grooved water-lubricated journal bearings under dynamic load. 
Proc Inst Mech Eng Part J J Eng Tribol 2008;222:683-91. https://doi.org/10.1243/13506501JET356.

32. Wang N, Meng Q, Wang P, Geng T, Yuan X. Experimental Research on Film Pressure Distribution of WaterLubricated Rubber Bearing With Multiaxial Grooves. J Fluids Eng n.d.;2013.

33. Pai R, Hargreaves DJ, Brown R. Modelling of fluid flow in a 3-axial groove water bearing using computational fluid dynamics. 14 th Australas. Fluid Mech. Conf., 2001.

34. Wang Y-Q, Shi X-J, Zhang L-J. Experimental and numerical study on water-lubricated rubber bearings. Ind Lubr Tribol 2014;66:282-8. https://doi.org/10.1108/ILT-11-2011-0098.

35. Brito FP, Miranda AS, Claro JCP, Fillon M. Experimental comparison of the performance of a journal bearing with a single and a twin axial groove configuration. Tribol Int 2012;54:1-8. https://doi.org/10.1016/J. TRIBOINT.2012.04.026.

36. Hirani H, Verma M. Tribological study of elastomeric bearings for marine propeller shaft system. Tribol Int 2009;42:378-90. https://doi.org/10.1016/j. triboint.2008.07.014

37. He Y, Zhao Z, Luo T, Lu X, Luo J. Failure analysis of journal bearing used in turboset of a power plant. Mater Des 2013;52:923-31. https://doi.org/10.1016/J. MATDES.2013.06.027.

38. Mehdizadeh M, Khodabakhshi F. An investigation into failure analysis of interfering part of a steam turbine journal bearing. Case Stud Eng Fail Anal 2014;2:61-8. https://doi. org/10.1016/J.CSEFA.2014.04.001.

39. Branagan L, Branagan, A. L. Survey of Damage Investigation of Babbitted Industrial Bearings. Lubricants 2015;3:91-112. https://doi.org/10.3390/lubricants3020091.

40. Akagaki T, Kato K. Ferrographic analysis of failure process in a full-scale journal bearing. Wear 1992;152:241-52. https://doi.org/10.1016/0043-1648(92)90123-P.

41. Wang Q. Seizure failure of journal-bearing conformal contacts. Wear 1997;210:8-16. https://doi.org/10.1016/ S0043-1648(97)00064-1.

42. Litwin W, Olszewski A. Assessment of possible application of water-lubricated sintered brass slide bearing for marine propeller shaft. POLISH Marit Res 2012;19:54-61. https:// doi.org/10.2478/v10012-012-0040-4.

43. Takabi J, Khonsari MM. On the thermally-induced seizure in bearings: A review. Tribol Int 2015;91:118-30. https:// doi.org/10.1016/J.TRIBOINT.2015.05.030.
44. Laukiavich CA, Braun MJ, Chandy AJ. An Investigation into the Thermal Effects on a Hydrodynamic Bearing's Clearance. Tribol Trans 2015;58:980-1001. https://doi.org /10.1080/10402004.2015.1023408.

45. Litwin W, Dymarski C. Experimental research on waterlubricated marine stern tube bearings in conditions of improper lubrication and cooling causing rapid bush wear. Tribol Int 2016;95:449-55. https://doi.org/10.1016/j. triboint.2015.12.005.

46. Barszczewska A, Litwin W. Polymer journal bearings behaviour research under limited lubrication and cooling conditions conducted on high torque test rig. 16th EDFPPrime Work. "Behaviour J. thrust Bear. under transient Mix. Lubr. regime,” Poitiers, France: 2017, p. 24.

47. Zander N. Additive Manufacturing Materials and Technologies. STLE Tribol. Front. Conf., Chicago: 2018.

48. Barszczewska A, Piatkowska E, Litwin W. Selected Problems of Experimental Testing Marine Stern Tube Bearings. Polish Marit Res 2019;26:142-54. https://doi. org/10.2478/pomr-2019-0034.

49. Wodtke M, Litwin W. Water-lubricated stern tube bearing - experimental and theoretical investigations of thermal effects. Tribol Int 2021;153:106608. https://doi.org/10.1016/j. triboint.2020.106608.

\section{CONTACT WITH THE AUTHOR}

Agnieszka Barszczewska

e-mail:agnbarsz@pg.edu.pl

Gdańsk University of Technology,

Narutowicza 11/12

80-233 Gdańsk,

Poland 